\title{
Cognitive rehabilitation
}

\section{Literature review based on levels of evidence}

\author{
Patricia Regina Manzine ${ }^{1}$, Sofia Cristina Iost Pavarini ${ }^{2}$
}

\begin{abstract}
The aim of this study was to review the scientific publications on cognitive rehabilitation in Alzheimer's disease by year published and methodology employed. The principles of systematic review by the Brazilian Cochrane Center were used. Reviews conducted by this Center were identified together with those held on the LILACS and Medline scientific databases. Nine levels of evidence were considered for analysis and a total of 37 articles were found. The results showed a growing number of publications from 2001 onwards, with majority being published early this decade. Few studies have been published on cognitive rehabilitation, with an average of three articles published per year during the study period (1985-2008). The highest levels of evidence were observed in the more recently published studies. Cognitive rehabilitation can yield greater benefits in rehabilitating patients when associated with other forms of intervention. The latest studies demonstrating greater scientific evidence concluded that results remain limited and that further studies on the topic are needed.
\end{abstract}

Key words: elderly, dementia, Alzheimer's disease, rehabilitation.

Reabilitação cognitiva: um estudo de revisão baseada em níveis de evidência

Resumo - O objetivo foi revisar publicações científicas sobre reabilitação cognitiva na doença de Alzheimer segundo ano de publicação e rigor metodológico. Foram utilizados pressupostos da revisão sistemática do Centro Cochrane do Brasil. Foram identificados estudos de revisão já realizados por este Centro e incluídos estudos das bases LILACS e Medline. Nove níveis de evidência foram considerados para análise. Foram encontrados 37 artigos. Os resultados mostram uma crescente incidência de publicação a partir de 2001, com maior concentração no início desta década. São poucas ainda as publicações sobre reabilitação cognitiva, sendo uma média inferior a três artigos por ano no período estudado (1985-2008). Os maiores níveis de evidência foram observados nas publicações mais recentes. A reabilitação cognitiva quando em associação com outras intervenções pode apresentar maiores benefícios na reabilitação dos pacientes. Os estudos mais atuais e de maior evidência cientifica apontam que os resultados ainda são limitados e novas investigações são necessárias.

Palavras-chave: idoso, demência, doença de Alzheimer, reabilitação.

\section{Introduction}

The different dementia types all have the inherent characteristic of hampering the ability to learn new concepts and knowledge (Brandt and Rich, 1995). Alzheimer's disease $(\mathrm{AD})$ is the leading type of dementia in terms of number of cases diagnosed, and the disease has been identified as a looming public health issue.

One of the forms of Non Pharmacologic Treatment available is Neuropsychological Rehabilitation, an approach which encompasses a combination of psychotherapy, the therapeutic environment, family learning groups, schemes to instruct patients and cognitive rehabilitation. These proposals are all practiced and based on a multidisciplinary context.

Cognitive rehabilitation constitutes one of the components of neuropsychological rehabilitation (Prigatano, 1997; Ávila and Miotto, 2002). Its main objective is to empower patients and their family members to live together,

${ }^{1}$ Student in Nursing of the Federal University of São Carlos, São Paulo, SP, Brazil. FAPESP Grantholder. ${ }^{2}$ Nurse, Associate Professor of the Department of Nursing and Post-graduate Program in Nursing of the Federal University of São Carlos, São Paulo, SP, Brazil. Coordinator of the Graduate Course in Gerontology.

Sofia Cristina Iost Pavarini - Federal University of São Carlos - Rodovia Washington Luis km 335 - 13565-905 São Carlos SP - Brazil. E-mail: sofia@ufscar.br

Disclosure: The authors report no conflicts of interest.

Received July 01, 2009. Accepted in final form August 17, 2009. 
and to cope with, lessen or overcome the deficiencies and cognitive changes caused by neurologic lesions (Wilson, 1996; Ávila and Miotto, 2002). The focus of the majority of interventions proposed is to stimulate memory more effectively (Caliman and Oliveira, 2005). Cognitive rehabilitation "... involves identifying and guiding individual goals and needs, where this process calls for strategies to obtain new information or compensatory mechanisms such as the use of memory aids" (Clare and Wood, 2008, pg.2).

When used alone, these interventions have proven to be effective in many cases by avoiding or restricting the use of drugs, yet when combined with psychotropic medication, their benefits are potentially greater and can allow medication to be reduced or withdrawn altogether (Engelhardt et al., 2005). In addition, a balanced diet, physical exercises and supervision of daily activities are conducive to cognitive, behavioral and psychological rehabilitation (Bottino et al., 2002).

Thus, caring for $\mathrm{AD}$ patients entails a systematic and organized method, in a bid to provide individualized care focusing on the individual and group solutions. The execution of each step in assisting to care for AD patients implies evidence-based practice both in terms of the data gathered from the demented patient as well as the clinical decisions on the most efficacious treatment intervention (Galvão CM, Sawada NO, Rossi LA., 2002). The study of evidence-based practices first emerged in 1990 in the United Kingdom, the United States and Canada. In Brazil, this approach was first adopted in the medical community within the country's larger states and in São Paulo, Rio de Janeiro and Rio Grande do Sul State universities (Galvão C.M., Sawada N.O., Mendes I.A.C., 2003).

Evidence-based practice emerged with the aim of reaching consensus on the most relevant clinical data drawn from the results of studies and from information available on data bases, thus enabling explicit and criteria-based decision-making on specific care provided to individual patients or patient groups (Driever M.J., 2002).

The hierarchical organization of scientific evidence is dictated by the type of study design employed, i.e. of the methodological approach applied in the study (Humpris D., 1999). A classification which determines the quantitative and qualitative structure of studies is based on the categorizing of The Cochrane Collaboration, an international network which develops and disseminates systematic reviews on the effects of health interventions. Founded in 1993 in Oxford, this group comprises nine centers distributed world wide, one of which is the Cochrane Center of Brazil located in the city of São Paulo.

The methodology of the Cochrane Center of Brazil considers eight levels of evidence: Level 1, Systematic review and
Meta-analysis of controlled studies; Level 2, Randomized clinical trials; Level 3, Cohort studies; Level 4, Case-control studies; Level 5, Case series studies; Level 6, Case studies; Level 7, Research in animals and Level 8, Opinion of respected authorities/specialists (Higgins JPT, Green S., 2008).

Implementation of evidence-based practice enables the quality of care given to patient and family to be improved since this practice has a direct bearing on clinical decisions. Moreover, the professional also needs to develop the necessary skills and know-how to obtain, interpret and integrate evidence derived from studies based on the patient's data and clinical observations.

In a bid to find elements which can contribute to the implementation of public policies on care in demented elderly based on more explicit and qualified scientific decisions, this study sought to review scientific publications by assessing year of publication and levels of evidence on the theme of cognitive rehabilitation in elderly individuals with Alzheimer's disease.

\section{Methods}

An analytical bibliographic review was conducted based on the principles of the quantitative method of investigation. This study was supported by the funding body - Fundação de Amparo à Pesquisa do Estado de São Paulo (FAPESP).

The principles of the systematic review of the Cochrane Center of Brazil were used, whose objective is to pool and critically assess studies published on specific themes, determining the best levels of evidence. The first step of this study was to identify the Systematic Reviews conducted by the Cochrane Center of Brazil. For the target theme, the full Systematic Review entitled "Cognitive Rehabilitation and Cognitive Training for early-stage Alzheimer's disease and vascular dementia" was found on La Biblioteca Cochrane Plus and was duly included in this study along with its online references. Subsequently, studies retrieved from the LILACS and Medline primary data bases (1966-1996) and (1997-2008) were included, respectively. These data bases were chosen for their wide scope of national and international scientific articles available in the health area, and for their powerful search tools.

To perform the search, the key search words were first defined according to the Virtual Health Library (http:// www.bireme.br/php/index.php) at the DeCS link - Health Terminology (http://decs.bvs.br/) using the structured vocabulary in three languages (Portuguese, Spanish and English). The search strategy employed the terms "rehabilitation", "cognitive therapy", "combined therapy", "Alzheimer's disease", "elderly" and "elderly aged 80 years or older".

The Boolean Logic Operators "OR" - union or addition function, and "AND" for intersection of these terms, 
Table 1. Articles published, by level of evidence.

Systematic review and meta-analysis

2008 Cochrane Review Clare L, Woods $\mathrm{B}^{6}$

Literature review

2001 Cochrane Review

2002 LILACS

2002 Cochrane Review

2006 Medline

2006 Medline

2008 Medline

Randomized clinical trial

1999 Medline

2000 Cochrane Review

2001 Medline

2001 Cochrane Review

2003 Cochrane Review

2004 Medline

2004 Medline

2005 Medline

2005 Medline

2008 Medline

\section{Cohort study}

2008 Medline

\section{Case control study}

1996 Cochrane Review

Panza et al. ${ }^{34}$

2001 Cochrane Review

2001 Cochrane Review

2002 Cochrane Review

2006 Cochrane Review

2007 Medline

Zanetti et al. ${ }^{35}$

Kixmiller JS ${ }^{37}$

Knapp et al. ${ }^{38}$

Matsuda $\mathrm{O}^{39}$
Cognitive rehabilitation and cognitive training for early-stage Alzheimer's disease and vascular dementia
Bird $\mathrm{M}^{20}$

Ávila R, Miotto $\mathrm{E}^{3}$

Wilson $\mathrm{A}^{21}$

Burns A, Brien $\mathrm{JO}^{22}$

Sitzer DI, Twamley EW, Jeste DV 23

Hogan DB et al. ${ }^{24}$

Corbeil RR et al. ${ }^{25}$

Quayhagen et al. ${ }^{26}$

Davis et al. ${ }^{27}$

Koltai t al. ${ }^{17}$

Spector et al. ${ }^{19}$

Chapman SB et al. ${ }^{28}$

Olazarán et al. ${ }^{29}$

Onder G et al. ${ }^{30}$

Bening et al. ${ }^{31}$

Meguro M et al. ${ }^{32}$

Gil P et al. ${ }^{33}$
Behavioural difficulties and cued recall of adaptive behaviour in dementia: experimental and clinical evidence

Neuropsychological rehabilitaion of memory's impairments in patients with Alzheimer's disease

Towards a comprehensive model of cognitive rehabilitation

Clinical practice with anti-dementia drugs: a consensual statement from British Association for Psychopharmacology

Cognitive training in Alzheimer's disease: a meta-analysis of the literature

Diagnosis and treatment of dementia: approach to management of mild to moderate dementia

Intervention effects on dementia caregiving interaction

Coping with dementia: evaluation of four nonpharmacologic interventions

Cognitive intervention in Alzheimer disease: a randomized placebo-controlled study Influence of anosognosia on treatment outcome among dementia patients

Efficacy of an evidence-based cognitive stimulation therapy programme for people with dementia

Effects of cognitive-communication stimulation for Alzheimer's disease patients treated with donepezil

Benefits of cognitive-motor intervention in MCI and mild to moderate Alzheimer's disease

Reality orientation therapy combined with cholinesterase inhibitors in Alzheimer's disease: randomized controlled trial

Cognitive rehabilitation combined with drug treatment in Alzheimer's disease patients: a pilot study

Comprehensive approach of donepezil and psychosocial interventions on cognitive function and quality of life for Alzheimer's disease: the Osaki-Tajiri Project

Variability in the diagnosis and management of patients with Alzheimer's disease and cerebrovascular disease

A rehabilitation program for mild memory impairments

Effectiveness of procedural memory stimulation in mild Alzheimer's disease patients: a controlled study

Moore S et al. ${ }^{36} \quad$ Memory training improves cognitive ability in patients with dementia

Evaluation of prospective memory training for individuals with mild Alzheimer's disease
Cognitive stimulation therapy for people with dementia: cost-effectiveness analysis

Cognitive stimulation therapy for Alzheimer's disease: the effect of cognitive stimulation therapy on the progression of mild Alzheimer's disease in patients treated with donepezil 
Table 1. Continuation.

\begin{tabular}{|c|c|c|c|}
\hline \multicolumn{4}{|c|}{ Case series study } \\
\hline 1991 & Cochrane Review & Backman L. et al. ${ }^{40}$ & $\begin{array}{l}\text { The generalizability of training gains in dementia: effects of an imagery-based mne- } \\
\text { monic on face-name retention duration }\end{array}$ \\
\hline 1996 & Cochrane Review & Hofmann et al. ${ }^{41}$ & Interactive computer-based cognitive training in patients with Alzheimer's disease \\
\hline 1997 & Cochrane Review & Zanotti et al. ${ }^{42}$ & $\begin{array}{l}\text { Procedural memory stimulation in Alzheimer's disease: impact of a training pro- } \\
\text { gramme }\end{array}$ \\
\hline 2002 & LILACS & Bottino et al. ${ }^{8}$ & $\begin{array}{l}\text { Cognitive rehabilitation in patients with Alzheimer's disease - work's report in mul- } \\
\text { tidisciplinary team }\end{array}$ \\
\hline 2002 & Medline & Clare L et al. ${ }^{43}$ & Relearning face-name associations in early Alzheimer's disease \\
\hline 2002 & Medline & $\begin{array}{c}\text { Farina E, } \\
\text { Fioravanti R, } \\
\text { Chiavari L, et al. }{ }^{18}\end{array}$ & Comparing two programs of cognitive training in Alzheimer's disease: a pilot study \\
\hline 2003 & Medline & $\begin{array}{l}\text { Mahendra N, } \\
\text { Arkin } \mathrm{S}^{44}\end{array}$ & Effects of four years of exercise, language, and social interventions on Alzheimer discourse \\
\hline 2007 & Medline & Baldelli et al. ${ }^{45}$ & Occupational therapy and dementia: the experience of an Alzheimer special care unit \\
\hline \multicolumn{4}{|c|}{ Case study } \\
\hline 1987 & Cochrane Review & Hill et al. ${ }^{46}$ & Imagery mnemonic training in a patient with primary degenerative dementia \\
\hline 2001 & Cochrane Review & Clare L et al. ${ }^{16}$ & $\begin{array}{l}\text { Long-term maintenance of treatment gains following a cognitive rehabilitation inter- } \\
\text { vention in early dementia of Alzheimer type: a single case study }\end{array}$ \\
\hline 2003 & LILACS & Avila $\mathrm{R}^{47}$ & Neuropsychological rehabilitaion results in patients with mild Alzheimer's disease \\
\hline 2003 & Medline & Clare L et al. ${ }^{48}$ & $\begin{array}{l}\text { Cognitive rehabilitation as a component of early intervention in Alzheimer's disease: } \\
\text { a single case study }\end{array}$ \\
\hline \multicolumn{4}{|c|}{ Opinion of specialist } \\
\hline 2002 & Medline & Burns $\mathrm{AS}^{49}$ & Meaningful treatment outcomes in Alzheimer's disease \\
\hline
\end{tabular}

were added to connect the key words and synonyms of each language.

\section{Outline of search strategy}

The inclusion criteria of articles comprised: publications between January 1985 and December 2008, theme of cognitive rehabilitation in the context of dementia (Alzheimer) in the elderly, and presentation in the form "Full text free". Nine levels of evidence were considered for analysis. Given the current divergence in the concepts of Systematic Review and Literature Review, we elected to differentiate these two methodologies for the purposes of analysis, by assigning them separate categories. This gave the following nine levels: Systematic review and Meta-analysis, Review of the literature, Randomized clinical trial, Cohort study, Case-controlled study, Case series studies, Casestudy, Research in animals, and Opinion of specialist.

\section{Results}

Table 1 presents the 37 articles matching the study inclusion criteria. From among these (Systematic Review included), 15 were reference studies retrieved by the Systematic Review, 18 were articles found on the Medline data base (1997-2008) and three were found on the LILACS data base. No articles from the Medline data base (19661996) met the inclusion criteria.

The data found revealed that a mean of approximately 2.64 articles were published per year over the period spanning 1985 to 2008. Regarding the distribution of annual publications, the standard deviation was 1.94, a figure which denotes data spread centered around the mean ( $\mathrm{Pa}$ gano and Gauvreau, 2004).

The data showed that publications on cognitive rehabilitation remain low, with a mean of less than three articles published annually for the study period. In line with that proposed by other authors, there is a need for further studies on this subject seeking more in-depth evidence.

As shown in Table 2, the highest prevalence of articles was observed in 2002 (19\%) followed by 2001 ( $n=6$ or 16\%), 2004 and 2008, both with four studies (11\% each). 
Table 2. Relationship between number and year of studies based on search methodology.

\begin{tabular}{ccc}
\hline Year & Number of studies & $\%$ \\
\hline 1987 & 1 & 2.70 \\
1991 & 1 & 2.70 \\
1996 & 2 & 5.41 \\
1997 & 1 & 2.70 \\
1999 & 1 & 2.70 \\
2000 & 1 & 2.70 \\
2001 & 6 & 16.22 \\
2002 & 7 & 18.92 \\
2003 & 4 & 10.81 \\
2004 & 2 & 5.41 \\
2005 & 2 & 5.41 \\
2006 & 3 & 8.11 \\
2007 & 2 & 5.41 \\
2008 & 4 & 10.81 \\
& 37 & $100 \%$ \\
\hline
\end{tabular}

No studies were found for the years not listed above.

A growing rate of publication on the subject was observed after the turn of the twenty first century, with articles found for each year thereafter $(2000,2001,2002,2003$, 2004, 2005, 2006, 2007 and 2008), representing the opposite pattern to the preceding nineteenth century during which, articles presented greater time intervals between publications (1987, 1991, 1996, 1997 and 1999), thus demonstrating the growing importance and concern of scientific output on the topic of care for $\mathrm{AD}$ patients and those involved (caregivers, family members, researchers) over recent years. The results indicate a trend toward more frequent studies from 2001 onward.

The data show a linear growth trend in the number of studies published each year, as illustrated in Figure 1.

It is important to note that, of the six articles published in 2001, five were from the same specific period and that the present study found no reason for the high number of publications in 2002.

In terms of levels of evidence, of the 37 studies found, a mean of approximately 4.12 studies per level of evidence were obtained, with a respective standard deviation of approximately 3.58 .

One study presented the highest level of epidemiological evidence from the scientific literature, namely, the Systematic Review study, where this accounted for $2.7 \%$ of the articles. The same statistical proportion of $2.7 \%$ was seen for Cohort studies and Opinion of Specialist levels.

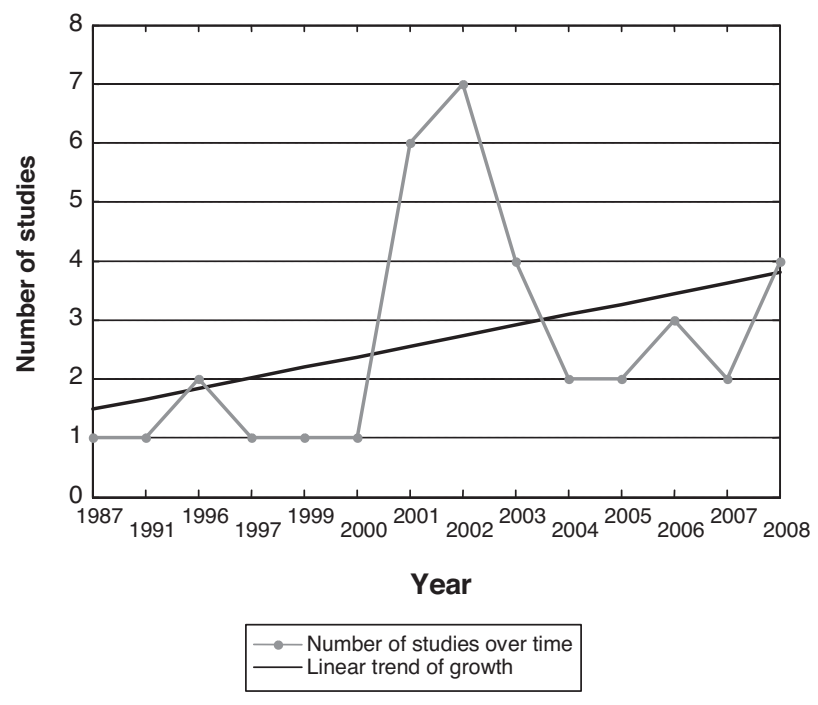

Figure 1. Relationship between number and year of studies found based on the search methodology.

Table 3. Relationship between number and levels of evidence of studies found based on search methodology.

\begin{tabular}{lcc}
\hline Levels of evidence & $\begin{array}{c}\text { Number of } \\
\text { studies }\end{array}$ & $\%$ \\
\hline Systematic review or meta-analysis & 1 & $2.70 \%$ \\
Review of the literature & 6 & $16.22 \%$ \\
Randomized clinical trial & 10 & $27.03 \%$ \\
Cohort study & 1 & $2.70 \%$ \\
Case-control study & 6 & $16.22 \%$ \\
Case series study & 8 & $21.62 \%$ \\
Case study & 4 & $10.81 \%$ \\
Research in animals & 0 & $0.00 \%$ \\
Opinion of specialist & 1 & $2.70 \%$ \\
& 37 & $\mathbf{1 0 0} \%$ \\
\hline
\end{tabular}

In decreasing order of methodological merit, after the Systematic Review studies, the studies with the greatest number of quantitative findings were as follows: the Literature Review level with 16\% (N=6), Randomized clinical trials with $27 \%(\mathrm{~N}=10)$, Case-Control study $(\mathrm{N}=6)$, accounting for $16 \%$, and Case Series studies representing $22 \%$ of the total $(\mathrm{N}=8)$.

The Case study articles represented $11 \%$ of the sample found $(\mathrm{N}=4)$, as shown in Table 3 and Figure 2. In addition, no articles for the Research in Animals level were found $(\mathrm{N}=0)$.

Overall, the scientific output for the subject of cognitive rehabilitation in $\mathrm{AD}$ patients presented a balanced dis- 


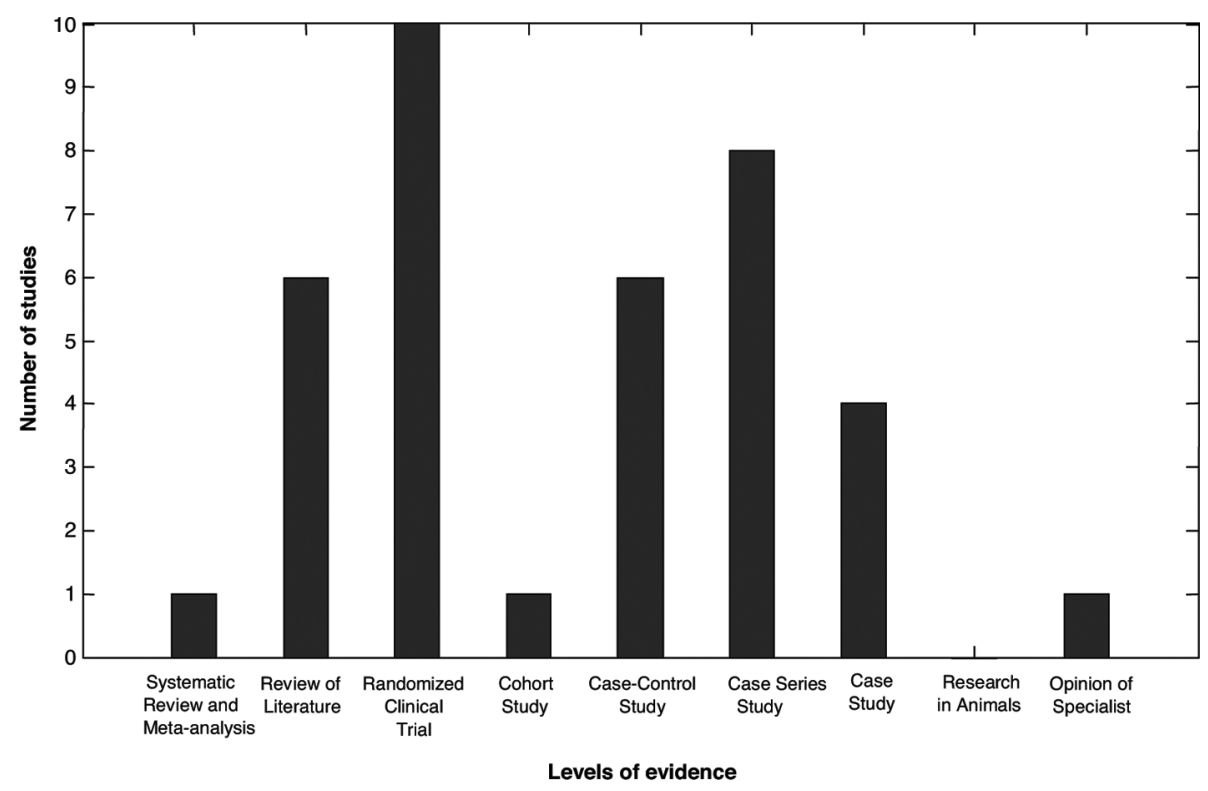

Figure 2. Relationship between number and level of evidence of studies found based on search methodology.

tribution of evidence levels of greater and lesser research relevance. However, articles employing better planned and designed scientific methodologies are needed based on the investigations currently available on the subject (Opie et al., 1999; Clare et al., 2001; Koltai et al., 2001; Farina et al., 2002; Spector et al., 2003; Clare L., Woods B., 2008).

The data obtained revealed that few studies on cognitive rehabilitation were published in the twentieth century. Studies published during this period included: one Randomized Clinical Trial (1999), one Case Control study (1996), three Case Series studies (1991, 1996 and 1997) along with the earliest study found (1987) which was a Case Study.

The results demonstrated that the only article with a high level of evidence (Systematic Review) was published in 2008. The first Review of the Literature study was produced in $2001(\mathrm{~N}=1)$ followed by two further articles in 2002, two in 2006 and one in 2008.

In decreasing order of scientific relevance, nine Randomized Clinical Trials were found (one in 2000, two in 2001, one in 2003, two in 2004, two in 2005 and one in 2008), plus one Cohort Study (2008), five Case-Control Studies (two in 2001, one in 2002, one in 2006 and one in 2007), five Case Series Studies (three in 2002, one in 2003 and one in 2007), three Case Studies (one in 2001 and two in 2003), while no studies at the Research in Animals level was found. Only one study for Specialist Opinion level was found (2002).

The results showed an increase in scientific output from the beginning of the twenty-first century on the theme of cognitive rehabilitation in the elderly with Alzheimer type dementia, while the highest levels of evidence were observed in the more recent publications.

Notably, among the studies analyzed, the association between pharmacologic therapy and cognitive rehabilitation was described at various different levels of scientific evidence since 2001.

The majority of researchers suggested that cognitive rehabilitation can better benefit patient rehabilitation when combined with other interventions such as pharmacologic treatment, interventions involving family members and environmental interventions. The latest studies demonstrating greater scientific evidence concluded that results of studies remain limited and that further investigation on the topic is needed.

\section{Discussion}

The increased prevalence of dementias has driven the need for further research in this area. The results demonstrated an increase in scientific output from 2001 on the theme of cognitive rehabilitation in the elderly with $\mathrm{Al}-$ zheimer type dementia.

The highest levels of evidence were observed in the more recent publications, thereby demonstrating the growing importance and concern in recent years of the scientific output addressing the care and assistance of patients with Alzheimer's disease as well as of caregivers, family and health professionals involved with the disease. Furthermore, these findings support the development and growth of implementation of evidence-based practices across all 
fields of health research, so as to ensure more qualified and scientifically-based care and intervention.

Future studies are needed investigating cognitive rehabilitation in Alzheimer Disease patients, to pool and disseminate the aspects and concepts present among the highest levels of evidence, both in the context of data and information acquired from demented individuals, as well as towards implementing the best treatment interventions through well-informed clinical decisions.

More in-depth studies are warranted to build on the contributions made by these articles to cognitive rehabilitation and its applicability in caring for demented elderly.

Grant supports - Study carried out with financial support of FAPESP. Health and Aging Research Group - CNPq

\section{References}

1. Brandt J, Rich JB. Memory disorders in the dementias. In: Baddeley AD, Wilson BA, Watts FN, Editors. Handbbok of Memory Disorders. Chichester: John Wiley \& Sons Ltd; 1995.

2. Prigatano GP. Learning from our Successes and Failures: Reflections and Comments on "Cognitive Rehabilitation: How it is and How it Might Be". J Int Neuropsychol Soc 1997;3:497-499.

3. Ávila R, Miotto E. Reabilitação neuropsicológica de déficits de memória em pacientes com demência de Alzheimer. Rev Psiq Clín 2002;29:190-196.

4. Wilson BA. Reabilitação das deficiências cognitivas. In: Nitrini R, Caramelli P, Mansur LL, Editores. Neuropsicologia das bases anatômicas à reabilitação. Clínica Neurológica 1996; 314-343.

5. Caliman GT, Oliveira RMW. Novas perspectivas no tratamento da doença de Alzheimer. Iniciação Científica CESUMAR 2005:141-162.

6. Clare L, Woods B. Cognitive rehabilitation and cognitive training for early-stage Alzheimer's disease and vascular dementia (Cochrane Review). The Cochrane Library 2008;4. Oxford: Update Software.

7. Engelhardt E, Brucki SM, Cavalcanti JL, Forlenza OV, Laks J, Vale FA. Departamento de Neurologia Cognitiva e do Envelhecimento da Academia Brasileira de Neurologia. [Treatment of Alzheimer's disease: recommendations and suggestions of the Scientific Department of Cognitive Neurology and Aging of the Brazilian Academy of Neurology. Arq Neuropsiquiatr 2005;63:1104-112

8. Bottino C, Carvalho I, Alvarez, et al. Reabilitação cognitiva em pacientes com doença de Alzheimer: relato de trabalho em equipe multidisciplinar. Arq Neuropsiquiatr 2002;60:70-79.

9. Galvão CM, Sawada NO, Rossi LA. A prática baseada em evidências: considerações teóricas para sua implementação na enfermagem perioperatória. Rev Latino-Am Enfermagem 2002;10:690-695.

10. Galvão CM, Sawada NO, Mendes IAC. A busca das melhores evidências. Rev Esc Enferm USP 2003;37:43-50.

11. Driever MJ. Are evidence-based practice and best practice the same? West J Nurs Res 2002;24:591-597.

12. Humpris D. Types of evidence. In: Hamer S, Collinson G, Editors. Achieving evidence-based practice: a handbook for practitioners. Baillière Tindall; 1999:13-40.

13. Higgins JPT, Green S. (editors). Cochrane Handbook for Systematic Reviews of Interventions Version 5.0.1 [updated September 2008]. The Cochrane Collaboration, 2008. Available from www.cochrane-handbook.org.

14. Pagano M, Gauvreau K. Princípios de Bioestatística, 2a ed. São Paulo: Pioneira Thomson Learning; 2004.

15. Opie J, Rosewarne R, O'Connor DW. The efficacy of psychosocial approaches to behaviour disorders in dementia: a systematic literature review. Aust N Z J Psychiatry 1999;33:789-799.

16. Clare L, Wilson BA, Carter G, Hodges JR, Adams M. Longterm maintenance of treatment gains following a cognitive rehabilitation intervention in early dementia of Alzheimer type: a single case study. Neuropsychol Rehabil 2001;11:477-494.

17. Koltai DC, Bohmer KAW, Schmechel DE. Influence of anosognosia on treatment outcome among dementia patients. Neuropsychol Rehabil 2001;11:455-475.

18. Farina E, Fioravanti R, Chiavari L, et al. Comparing two programs of cognitive training in Alzheimer's disease: a pilot study. Acta Neurol Scand 2002;105:365-371.

19. Spector A, Thorgrimsen L, Woods B, et al. Efficacy of an evidence-based cognitive stimulation therapy programme for people with dementia. Brit J Psychiatry 2003;183:248-254.

20. Bird M. Behavioural difficulties and cued recall of adaptive behaviour in dementia: Experimental and clinical evidence. Neuropsychol Rehabil 2001;11:357-375.

21. Wilson BA. Towards a comprehensive model of cognitive rehabilitation. Neuropsychol rehabil 2002;12:97-110.

22. Burns A. Meaningful treatment outcomes in Alzheimer's disease. J Neurol Neurosurg Psychiatry 2002;73:471-472.

23. Sitzer DI, Twamley EW, Jeste DV. Cognitive training in Alzheimer's disease: a meta-analysis of the literature. Acta Psychiatr Scand 2006;114:75-90.

24. Hogan DB, Bailey P, Black S, et al. Diagnosis and treatment of dementia: Approach to management of mild to moderate dementia. CMAJ 2008;179:787-793.

25. Corbeil RR, Quayhagen MP, Quayhagen M. Interventions effects on dementia caregiving interaction: a stress-adaptation modeling approach. J Aging Health 1999;11:79-95.

26. Quayhagen MP, Quayhagen M, Corbeil RR, et al. Coping with Dementia: Evaluation of Four Nonpharmacologic Interventions. Int Psychogeriatr 2000;12:249-265.

27. Davis RN, Massman PJ, Doody RS. Cognitive Intervention in 
Alzheimer Disease: A Randomized Placebo-Controlled Study. Alzheimer Dis Assoc Disord 2001;15:1-9.

28. Chapman SB, Weiner MF, Rackley A, Hynan L, Zientz J. Effects of Cognitive-Communication Stimulation for Alzheimer's Disease Patients Treated With Donepezil. J Speech Lang Hear Res 2004;47:1149-1163.

29. Olazarán J, Muniz R, Reisberg B, et al. Benefits of cognitivemotor intervention in MCI and mild to moderate Alzheimer disease. Neurology 2004;63:2348-2353.

30. Onder G, Zanetti O, Giacobini E, et al. Reality orientation therapy combined with cholinesterase inhibitors in Alzheimer's disease: randomized controlled trial. Br J Psychiatry 2005; 187:450-455.

31. Bottino C, Carvalho I, Alvarez AM, et al. Cognitive rehabilitation combined with drug treatment in Alzheimer's disease patients: a pilot study. Clin Rehabil 2005;19:861-869.

32. Meguro M, Kasai M, Akanuma K, Ishii H, Yamaguchi S, Meguro K. Comprehensive approach of donepezil and psychosocial interventions on cognitive function and quality of life for Alzheimer's disease: the Osaki-Tajiri Project. Age Ageing 2008;37:469-473.

33. Gil P, Ayuso JLD, Marey JM, Antón M, Quilo CG. Variability in the diagnosis and management of patients with Alzheimer's disease and cerebrovascular disease. Clin Drug Invest 2008; 28:429-437.

34. Panza F, Solfrizzi V, Mastroiani F, Nardó GA, Cigliola F, Capurso A. A rehabilitation program for mild memory impairments. Arch Gerontol Geriatr 1996;22(suppl 1):51-55.

35. Zanetti O, Zanieri G, Giovanni GD, et al. Effectiveness of procedural memory stimulation in mild Alzheimer's disease patients: A controlled study. Neuropsychol Rehabil 2001;11:263-272.

36. Moore S, Sandman CA, McGrady K, Kesslak JP. Memory training improves cognitive ability in patients with dementia. Neuropsychol Rehabil 2001;11:245-261.

37. Kixmiller JS. Evaluation of prospective memory training for individuals with mild Alzheimer's disease. Brain Cogn 2002; 49:237-241.

38. Knapp M, Thorgrimsen L, Patel A, et al. Cognitive stimulation therapy for people with dementia: cost-effectiveness analysis. Br J Psychiatry 2006;188:574-580.

39. Matsuda O. Cognitive stimulation therapy for Alzheimer's disease: the effect of cognitive stimulation therapy on the progression of mild Alzheimer's disease in patients treated with donepezil. Int Psychogeriatr 2007;19:241-252.

40. Backman L, Josephsson S, Herlitz A, Stigsdotter A. The generalizability of training gains in dementia: effects of an imagerybased mnemonic on face-name retention duration. Psychol Aging 1991;6:489-492.

41. Hofmann M, Hock C, Kuhler A, Muller-Spahn F. Interactive computer-based cognitive training in patients with Alzheimer's disease. J Psychiat Res 1996;30:493-501.

42. Zanetti O, Binetti G, Magni E, Rozzini L, Bianchetti A, Trabucchi M. Procedural memory stimulation in Alzheimer's disease: impact of a training programme. Acta Neurol Scand 1997;95:152-157.

43. Clare L, Wilson BA, Carter G, Roth I, Hodges JR. Relearning face-name associations in early Alzheimer's Disease. Neuropsychology 2002;16:538-547.

44. Mahendra N, Arkin S. Effects of four years of exercise, language, and social interventions on Alzheimer discourse. J Commun Disord 2003;36:395-422.

45. Baldelli MV, Pradelli JM, Zucchi P, Martini B, Orsi F, Fabbo A. Occupational therapy and dementia: the experience of an Alzheimer special care unit. Arch Gerontol Geriatr 2007;(Suppl 1):49-54.

46. Hill RD, Evankovich KD, Sheikh JI, Yesavage JA. Imagery mnemonic training in a patient with primary degenerative dementia. Psychol Aging 1987;2:204-205.

47. Ávila R. Resultados da reabilitação neuropsicológica em pacientes com doença de Alzheimer leve. Rev Psiq Clín 2003; 30:139-146.

48. Clare L, Wilson BA, Carter G, Hodges JR. Cognitive rehabilitation as a component of early intervention in Alzheimer's disease: a single case study. Aging Ment Health 2003;7:15-21.

49. Burns A, O’Brien J. Clinical practice with anti-dementia drugs: a consensus statement from British Association for Psychopharmacology. J Psychopharmacol 2006;20:732-755. 